\title{
O DESAFIO DA ATUALIZAÇÃO DOS CONCEITOS DE RURAL E CAMPO NOS LIVROS DIDÁTICOS DE GEOGRAFIA FRENTE ÀS DINÂMICAS ATUAIS DE TRANSFORMAÇÃO ESPACIAL
}

The challenge to update the rural and field concepts in the Geography's Textbooks because of the current dynamics of spatial transformation

Maria Rita Ivo de Melo Machado

Prof. ${ }^{a}$ do Dept ${ }^{\mathrm{o}}$ História da Universidade Federal Rural de Pernambuco, na área de Geografia mariaritamachado@yahoo.com.br

Mariana Zerbone Alves de Albuquerque

Prof. ${ }^{a}$ do Dept $^{\circ}$ História da Universidade Federal Rural de Pernambuco, na área de Geografia mzerbone@hotmail.com

Artigo recebido em 07/04/2016 e aceito para publicação em 25/05/2016

DOI: $10.12957 /$ tamoios.2016.22351

Resumo

Abstract
As relações rural-urbano, campo-cidade, paisagem urbana e paisagem rural devem ser abordadas no ensino da Geografia Escolar, no segundo ciclo (ou seja, nas turmas do $4^{\circ}$ ao $5^{\circ}$ ano), de acordo com os PCNs de Geografia. Frente a essa velocidade dos acontecimentos em um mundo globalizado, emerge o desafio de atualização de conceitos a partir de transformações práticas e reais do/no espaço, como o que vem a ser "rural", foco desta pesquisa. Contudo, a partir de análises de livros didáticos de geografia, tem-se percebido alguns problemas na conceituação e na abordagem sobre o rural na geografia. É a partir desta perspectiva que esta pesquisa tem como objetivo analisar se os livros didáticos do $4^{\circ}$ ao $5^{\circ}$ ano conseguem explicitar as múltiplas dinâmicas socioeconômicas existentes no espaço rural, além de possibilitar ao aluno a compreensão dos conceitos de rural e de campo. Para desenvolver esta pesquisa foi realizado um resgate teórico a fím de compreender os conceitos de rural e campo, além da análise de duas coleções de livros didáticos comercializados em Pernambuco, com o intuito de realizar análises críticas sobre como esses livros didáticos têm contribuído para a compreensão do rural a partir das dinâmicas atuais de transformação espacial.

Palavras-chave: Rural; Livro Didático; Paisagem.

The rural-urban relationships, city-countryside, urban and rural landscapes should be addressed in the teaching of Geography School, in the second cycle (classes from the 4th to 5th year), according to the Curricular Parameters of Geography. Faced with this speed of events in a globalized world, emerges the challenge of updating concepts from practical changes and real space, like what does "rural", focus of this research. However, from geography textbooks analysis, we have observed some problems in the conceptualization and approach on rural in the geography. It is from this perspective that this research is to analyze whether the textbooks from the 4th to 5th year can explain the multiple socioeconomic dynamics existing in rural areas, and enable the students to understand the concepts of rural and field. To develop this research was carried out a theoretical rescue in order to understand the concepts of rural and countryside, as well as analysis of two collections of textbooks sold in Pernambuco, in order to perform critical analysis of how these textbooks have contributed to the understanding rural from the current dynamics of spatial transformation.

Palavras-chave: Rural geography textbooks; Landscape. 


\section{INTRODUÇÃO}

Abordagens atuais da Geografia têm buscado práticas pedagógicas que permitam que os alunos desenvolvam a capacidade de identificar e refletir sobre diferentes aspectos da realidade, compreendendo a relação sociedade/natureza. Nessa perspectiva, a geografia aborda uma realidade dinâmica, complexa e pautada em relações dialéticas de transformação do espaço. Desta maneira, é recorrente a necessidade de revisão e atualização de conceitos e categorias de análise, visto que a geografia tem como campo de análise o espaço, sendo este entendido como condição, meio e produto das relações sociais (CARLOS, 2005), em que em tempos de globalização se apresenta articulado em diferentes escalas temporais e espaciais. Deste modo, a primeira inquietação é se frente a esta atual dinâmica dos acontecimentos, como se dá a atualização dos conceitos e como são estabelecidas as análises nos livros didáticos de geografia a partir de transformações práticas e reais do/no espaço? Foco desta pesquisa. De acordo com Albuquerque (2014):

O que se percebe é que a geografia vem passando por diversas transformações teórico-metodológicas desde quando se consolida como ciência em meados do século XIX, dando origem a diferentes correntes de pensamento da geografia: tradicional, teórico-quantitativa e crítica. No entanto o ensino da geografia nas escolas não sofreu grandes transformações no decorrer do tempo, não acompanhando as novas perspectivas teórico-metodológicas elaboradas da geografia enquanto ciência. (ALBUQUERQUE, 2014, p. 31)

Dentre os vários conceitos que sofrem transformações com a dinâmica da globalização, pode-se elencar os conceitos de campo e cidade e rural e urbano. Cada vez mais esses espaços são modificados pelas relações entre fixos e fluxos que se estabelecem em diferentes escalas e com a inserção de novas técnicas e tecnologias, como também novas funções, porém com resistências e permanências. Essa dinâmica espacial e conceitual, contudo, nem sempre é retratada nos livros didáticos. Então, a segunda inquietação é: como são abordadas estas novas relações entre campo-cidade e rural e urbano nos livros didáticos?

É importante destacar que as relações rural-urbano, campo-cidade, paisagem urbana e paisagem rural são abordadas desde cedo no ensino da Geografia Escolar, com ênfase no segundo ciclo, de acordo com os Parâmetros Curriculares Nacionais de Geografia, por ser um tema muito caro à Ciência Geográfica.

No segundo ciclo, o estudo da Geografia deve abordar principalmente as diferentes relações entre as cidades e o campo em suas dimensões sociais, culturais e ambientais e considerando o papel do trabalho, das tecnologias, da informação, da comunicação e do transporte. O objetivo central é que os alunos construam conhecimentos a respeito das categorias de paisagem urbana e paisagem rural, como foram constituídas ao longo do tempo e ainda o são, e como sintetizam múltiplos espaços geográficos. (BRASIL, 1998, p. 93)

Ainda de acordo com os PCNs de Geografia, observa-se a importância de se trabalhar, no segundo ciclo, a relação rural-urbano de maneira inter-relacionada e articulada, e não de forma dicotômica quando se afirma que "É possível, a partir de um estudo nessa escala, perceber como as paisagens urbanas e rurais foram se configurando e estão profundamente interligadas." (BRASIL, 1998). Contudo, a partir das análises de livros didáticos de geografia, tem-se percebido problemas na conceituação e na abordagem sobre o rural e campo, uma vez que a forma de análise da paisagem não 
possibilita aos alunos percebem as diversidades das paisagens e as inter-relações e articulações entre o rural e o urbano. É a partir desta perspectiva que esta pesquisa tem como objetivo analisar se os livros didáticos do $3^{\circ}$ ao $5^{\circ}$ ano do ensino fundamental I conseguem explicitar as múltiplas dinâmicas socioeconômicas existentes no campo, além de possibilitar ao aluno a construção dos conceitos de rural e de campo, levando em considerações as diretrizes dos Parâmetros Curriculares Nacionais, a fim de identificar os avanços, os problemas e até mesmo os equívocos ao abordar o rural e o campo. Este é um problema que já é apontado nos PCNs (BRASIL, 1998):

É importante ressaltar que o urbano e o rural são tradicionalmente trabalhados na escola. Entretanto, costuma-se estudar apenas suas características de forma descritiva e isolada, sem aprofundar temáticas que explicitem as relações de interdependência e de determinação que existem entre eles e enfocando-se quase que exclusivamente seus aspectos econômicos. (Op. Cit, p. 93)

A dificuldade dos livros didáticos em esclarecer o rural, assim como o campo, a cidade e o urbano, vai de encontro ao que solicita os Parâmetros Curriculares Nacionais, que dedica todo o seu segundo ciclo explicando a importância do esclarecimento das paisagens rurais, urbanas, suas características e relações. Contudo, apesar de apresentar as inter-relações entre campo-cidade, rural e urbano, os PCNs não definem o que vem a ser rural.

Atualmente, o urbano e o rural são compreendidos para além de seus aspectos econômicos ou da descrição compartimentada dos fenômenos sociais e naturais que os caracterizam. As múltiplas dinâmicas existentes entre as cidades e o campo; as semelhanças e diferenças entre os modos de vida que aí se constituem; as formas de trabalho e a produção e percepção do espaço e da paisagem; os relógios naturais e mecânicos que controlam a vida nas cidades e no campo e impõem ritmos de vida diferentes tornaram-se temas de investigação da própria Geografia e, na escola, se mostram interessantes e pertinentes de serem trabalhados, inclusive ao longo do segundo ciclo. (Op. Cit, 93)

Diante das fragilidades dos livros didáticos a respeito do conteúdo em questão e a partir do objetivo deste artigo, foram feitos alguns questionamentos: Como os livros didáticos esclarecem os conceitos de rural e de campo? Os livros didáticos conseguem abordar a complexidade e a diversidade de paisagens do campo? Os livros didáticos conseguem desenvolver a percepção de que o campo e a cidade estão interligados?

Com o intuito de responder a esses questionamentos e desenvolver a pesquisa, foram realizadas leituras bibliográficas de autores de diferentes áreas do conhecimento, e em especial da geografia, que buscam compreender os conceitos de rural, de campo e de urbano, com isso foi possível fazer uma análise crítica do que vem a ser o rural em tempos de globalização. Esse momento foi importante por entender que a discussão sobre os conceitos de rural e campo serve para desenvolver a compreensão da essência dos objetos, dos fenômenos que servem para a construção do conhecimento sobre o rural, o campo e suas inter-relações. Também tomou-se como base os Parâmetros Curriculares Nacionais de Geografia, a fim de compreender os direcionamentos institucionais a respeito de como esses conceitos devem ser abordados no ensino fundamental. A partir disso, identificou-se que os PCNs indicam abordagem satisfatória sobre o rural e o urbano.

O segundo momento foi o de análise de duas coleções de livros didáticos. Os livros foram escolhidos em função da comercialização. Os mais vendidos por duas 
importantes editoras do país no ano de 2014, no estado de Pernambuco, foram analisados. $\mathrm{Na}$ análise foram observadas as formas de abordagens das temáticas rurais $\mathrm{e}$ urbanas, além dos temas transversais. Após a identificação de como cada um dos livros das coleções abordam o rural e o urbano, foram realizadas análises críticas sobre como esses livros didáticos têm contribuído para a compreensão do rural e do campo a partir das dinâmicas atuais de transformação espacial.

\section{O RURAL E O CAMPO: UMA QUESTÃO CONCEITUAL}

Os espaços rurais e urbanos do Brasil tem passado, desde a década de 1960, por um conjunto de mudanças com significativo impacto sobre suas funções, territorialidades, paisagens, conteúdo social, relações e articulações. Este conjunto de transformações tem levado pesquisadores de diversas áreas a buscarem entender o que é o rural e o urbano nos dias de hoje. Entre os estudiosos de destaque na realização desta análise estão: Graziano da Silva (2002), Veiga (2002), Abramovay (2003) e Marques (2002).

Contudo, não só os teóricos tentam conceituar o que é o rural e o que é urbano, o que é campo e o que é cidade, mas o Estado também busca administrativamente definir o rural, o urbano e as suas múltiplas realidades e feições. Entre os motivos desta necessidade está o fato de planejar os diferentes espaços de acordo com as suas demandas, características e necessidades. O grande impasse na compreensão desses espaços pelo Estado está na forma como o Instituto Brasileiro de Geografia e Estatística (IBGE) identifica essas áreas. Para o IBGE:

"A classificação da situação do domicílio é urbana ou rural, segundo a
área de localização do domicílio, e tem por base a legislação vigente
por ocasião da realização do Censo Demográfico 1991. Como situação
urbana consideram-se as áreas correspondentes às cidades (sedes
municipais), às vilas (sedes distritais) ou às áreas urbanas isoladas. A
situação rural abrange toda a área situada fora desses limites. Este
critério é, também, utilizado na classificação da população urbana e
rural."
(http://www.ibge.gov.br/home/estatistica/populacao/mapa_mercado_tr
abalho/notastecnicas.shtm)

Como é possível ler na citação acima, o mesmo critério também é usado na classificação da população urbana e rural. Neste sentido, entende-se que o espaço rural, apesar de ser anterior ao espaço urbano no Brasil, é identificado apenas a partir do que não é urbano. E é esta perspectiva que os autores que debatem o rural buscam superar.

Analisando a partir da perspectiva acadêmica, Graziano da Silva (2002) menciona que o rural brasileiro é composto de quatro subconjuntos: a agropecuária moderna baseada em commodities, em atividades de subsistências, há também no espaço rural um conjunto de atividades não agrícolas (ligadas à moradia, lazer e a várias atividades industriais e prestações de serviços) e, por fim, a existência de novas atividades agropecuárias, localizadas em novos nichos de mercado. O prisma de José Graziano da Silva (2002), mostra que existe, no espaço rural, elementos que são classificados como tipicamente urbanos.

Para Veiga (2002) a identificação e diferenciação das áreas rurais e urbanas deve seguir o uso combinado dos seguintes critérios: tamanho populacional, densidade demográfica e localização. Ambos os critérios vão de encontro à delimitação políticoadministrativa imposta, em forma de dados oficiais, pelo IBGE. Na classificação deste órgão a identificação de rural e urbano é por exclusão. Tudo que não for urbano é rural. 
Para Abramovay (2000) a compreensão de rural e de urbano deve seguir uma análise territorial e não setorial. Antes de analisar as estatísticas sobre o rural e o urbano, deve-se saber o que se entende por "espaço rural", desde modo, a preocupação deve ficar menos nas definições e mais no sentido das ruralidades. Para este autor, há três formas dominantes de delimitação do rural e do urbano: a primeira é administrativa, ou seja, é a sede administrativa do município que define arbitrariamente qual parte de seu território é urbana ou rural; o segundo tipo de delimitação baseia-se na ocupação da mão-de-obra em atividades agrícolas ou não-agrícolas; já o terceiro e último critério de delimitação do rural e do urbano fundamenta-se num patamar populacional.

No entanto, o que se percebe no mundo globalizado de hoje é uma interferência cada vez maior do urbano no rural, com a ampliação do modo de vida urbano em áreas rurais, tornando o campo cada vez menos rural, mas sem deixar de ser campo. Este contexto se distancia, mas não anula a ideia de campo e cidade abordada por Marx e Engels no século XIX, onde "A cidade é de fato local de concentração de capital, da população, dos instrumentos de produção, dos prazeres e da necessidade, enquanto o campo mostra exatamente o fato oposto, isto é, o isolamento e a dispersão." (MARX e ENGELS, 2005). De acordo com Albuquerque e Machado (2015):

Hoje a ideia de urbano não se restringe apenas ao adensamento populacional, assim como a ideia de rural não está atrelada à escassez da ocupação humana. Para a compreensão de ambos espaços são levados em consideração elementos como: a produção, reprodução e circulação de mercadorias necessárias para a expansão do capital. (ALBUQUERQUE e MACHADO, 2015, p. 63)

Outros dois autores contribuem para uma melhor abordagem do que vem a ser rural e urbano em um mundo globalizado. Henri Lefebvre, quando aborda o que vem a ser urbano, deixando explicita a subordinação do campo a uma lógica do urbano em que "a produção agrícola se converte num setor da produção industrial" (2004, p. 17). Ele ainda afirma que:

Sobre essa relação campo-cidade, rural-urbano, Lefebvre afirma que:

Não há nenhuma razão teórica para se admitir o desaparecimento de uma centralização no decorrer de uma fusão da sociedade urbana com o campo. A oposição "urbanidade-ruralidade" se acentua em lugar de desaparecer, enquanto que a oposição cidade-campo se atenua. (LEFEBVRE, 2001, p. 69)

Ou seja, o mundo encontra-se cada vez mais pautado na dinâmica urbana, em que o rural é cada vez mais restrito, visto que o campo se integra na lógica da dinâmica urbana. No entanto, João Rua quando aborda a urbanidade no rural, e afirma que:

Um rural que interage como urbano, sem deixar de ser rural; transformado, não extinto. A hibridez perante evidencia a "criação local", a capacidade dos atores locais de ser influenciados pelo externo, de escala ampla, desenvolveram leituras particulares dessa influência e produzem territorialidades particulares. (RUA, 2006, p. 101)

Esses autores ajudam a compreender a inter-relação que se estabelece hoje entre rural e urbano, que não se apresenta de forma dicotômica, mas sim dialética, onde há articulações, mas também existem conflitos, gerando paisagens diversas no campo, mas com a predominância do crescimento da inserção do urbano no rural, contudo a escala 
de inter-relações entre rural e urbano não é homogênea. Deste modo, é necessário desmistificar a ideia do campo como sendo apenas o bucólico nos moldes do período da revolução industrial, e sim compreender os novos campos, para assim se livrar dos estereótipos, compreendendo as pluralidades e a diversidade desse espaço e suas paisagens.

Raymond Williams afirma que historicamente foram cristalizadas algumas ideias sobre campo que permanecem até hoje, como o campo "associado a uma forma natural de vida - de paz, inocência e virtudes simples.” (WILLIAMS, 2011, p. 11). No entanto, ele afirma que:

\begin{abstract}
A realidade histórica é surpreendentemente variada. A 'forma de vida campestre' engloba as mais diversas práticas - de caçadores, pastores, fazendeiros e empresários agroindustriais -, e sua organização varia da tribo ao feudo, do camponês e pequeno arrendatário à comuna rural, dos latifúndios e plantations às grandes empresas agroindustriais capitalistas fazendas estatais. (WILLIAMS, 2011, p.11)
\end{abstract}

Deste modo, entende-se que o campo é a área do rural onde as atividades econômicas e sociais se realizam. Nela existe uma grande diversidade social que está atrelada à natureza, "o que se reflete na complexidade de sua problemática social e ambiental, ao mesmo tempo em que representa um imenso potencial para o seu desenvolvimento" (MARQUES, 2002. P. 97). Ou seja, o campo é parte do rural, contudo o rural é mais amplo, pois integra o modo de vida, mas cada vez mais o campo tem incorporado práticas urbanas, com avanço das técnicas e da ciência, e sua articulação maior ao processo produtivo, até mesmo com a localização da própria indústria no campo. Nesse sentido, Marafon afirma que:

A análise das atuais transformações no campo brasileiro é fundamental, pois o campo, além de desempenhar as funções tradicionais de fornecer mão-de-obra e matérias-primas para a cidade e consumir produtos oriundos dela, abriga, cada vez mais, atividades não agrícolas, como a produção industrial e os serviços associados às atividades de turismo que valorizam as áreas com aspectos naturais. (MARAFON, 2010, p. 207)

Sobre essa nova lógica produtiva no campo, Denise Elias afirma que:

As novas possibilidades de fluidez do espaço, somadas às que a revolução tecnológica vem propiciando à intensificação da forma capitalista de produzir na agropecuária, promovem verdadeira reestruturação produtiva no setor. A partir desta reestruturação, muitos novos espaços agrícolas podem ser incorporados à produção e ao consumo agropecuários globalizados. (ELIAS, 2006, p. 31)

Contudo, mesmo frente a um grande processo de modernização do campo, é importante destacar que o campo não é homogêneo, o que engloba vários aspectos que caracterizam o campo. Marafon aponta para a diversidade deste campo, desde relações mais tradicionais a uma maior inter-relação com o urbano:

Configuram-se, então, novas relações entre o campo e a cidade, com novas qualidades e impressão de marcas fortes na paisagem. Além da produção agrícola e da industrialização, temos hoje novas atividades que devem ser identificadas para caracterizar o campo e suas relações com a cidade. A presença de uma enorme diversidade de atividades 
encontradas no campo decorre da ação dos pequenos produtores, que contribuem de forma significativa para a produção de alimentos e que, de forma criativa, traçam suas estratégias para sobreviver. No campo também há muitos sujeitos sociais, como os grandes proprietários, os assalariados, os pequenos proprietários, os parceiros, os trabalhadores volantes, os sem-terra e a sua luta pelo acesso à terra. Tais sujeitos materializam no espaço rural, com seu trabalho, uma ampla diversidade de objetos, elementos e situações que tornam o campo um espaço bastante complexo. (MARAFON, 2010, p. 208)

É preciso explicitar que o campo, seja no debate teórico, seja na questão político administrativa varia em suas formas efetivas de ocupação territorial, no seu contexto de transformações históricas e das suas concepções predominantes. Neste sentido, o campo pode se caracterizar pelo habitat concentrados em núcleos, que aglutina não somente as residências dos habitantes do campo, mas também as instituições públicas e privadas ligadas à vida local (WANDERLEY, 2000). O rural se estabelece como um modo de vida cada vez mais raro, em função da expansão do modo de vida urbano, contudo o campo permanece com sua diversidade e transformações, por ser o concreto, onde se estabelecem relações predominantes do setor primário da economia, porém cada vez mais articuladas aos setores secundários e terciários, com novas tecnologias e atendendo a demanda do urbano. Mas é importante lembrar que as ruralidades resistem a essas modificações, e que o importante nesse entendimento é compreender as multiplicidades de paisagens e não criar estereótipos desses espaços.

\section{UMA VISÃO PANORÂMICA DA ABORDAGEM DO RURAL NOS LIVROS DIDÁTICOS}

Entende-se que frente ao entendimento de rural e campo, a ideia de campo se sobressai, pois a dinâmica tem transformado estes espaços, tornando o campo menos rural, e mais agrícola com o advento das técnicas, contudo, a diversidade e desigualdade das práticas e paisagem do campo e rural não estão bem presentes, pois o espaço não é homogêneo.

O livro didático continua sendo um importante instrumento para o professor de ensino fundamental. Muitos ainda têm o livro didático como uma cartilha a ser seguida. Mesmo não estando de acordo que esse deva ser o único instrumento a ser utilizado pelo docente do ensino fundamental, é preciso que fique claro que para muitos este é a principal, e por vezes a única, fonte de conhecimento e a referência para os conteúdos a serem trabalhados com os alunos. Deste modo, é imprescindível que o livro didático traga abordagens conceituais pertinentes, atuais, sem estereótipos, e que estejam de acordo com as diretrizes dos PCNs, mas não é o que tem sido constatado. Desta maneira, buscou-se aqui fazer análise de duas coleções de editoras de caráter nacional. A primeira foi a Porta Aberta: geografia da FDT do $4^{\circ}$ ao $5^{\circ}$ Ano (2014) e o segundo foi Projeto Ápis da editora Ática, também do $4^{\circ}$ ao $5^{\circ}$ Ano (2014), a fim de verificar como os conceitos de rural e de campo estão sendo abordados nos livros didáticos. Albuquerque afirma que:

Em relação aos livros didáticos, como afirma Ariovaldo Umbelino de Oliveira (2008), estes são adotados como cartilhas por um grande contingente de professores do ensino escolar, os quais não conseguem se desprender deste material para extrapolar o conhecimento, não propiciando nem possibilitando a construção de um pensamento crítico por parte dos professores e consequentemente pelos alunos. De acordo com Antônio Carlos Robert de Moraes (2008), este quadro se consolida em função de obstáculo dos baixos salários e condições 
precárias de trabalho, elevadas cargas horárias, o que dificulta ultrapassar as barreiras implantadas, em busca de uma renovação do ensino da geografia. Muitas vezes é mais simples para o professor transmitir aquelas informações já prontas e acabadas que se encontra em manuais e cartilhas, utilizando-se de exercícios repetitivos e de memorização, do que promover uma construção das ideias e uma discussão sobre um tema a partir da vivência dos alunos, pois desta forma as deficiências do professor ficarão mais evidentes. (ALBUQUERQUE, 2014, p. 32)

A afirmação de que são apenas os livros didáticos que se equivocam ao conceituar como sinônimo campo e rural não é verdadeira. No meio acadêmico há ainda um extenso e contínuo debate sobre o esclarecimento desses conceitos, que precisam ter um fluxo contínuo de reflexões, uma vez que se tratam de espaços em eterno processo de transformação e de múltiplas identidades, por isso a necessidade de uma discussão teórica acerca desses conceitos, e de entender que eles são transformados de acordo com a análise da realidade.

Esclarecer esta diferença de usos das categorias rural e urbano e buscar definir-lhes um sentido é o objetivo deste ensaio interpretativo. Isto não significa uma pretensão ou busca de qualquer nova construção teórica mas, simplesmente, um esclarecimento terminológico, na tentativa de distinguir campo de rural, cidade de urbano. Importantes contribuições para o uso das expressões rural e urbano já foram fornecidas justamente pelos autores que aqui se pretende analisar. Porém, os mesmos que conseguiram realizar a dificílima tarefa de resignificar tais expressões e inseri-las como categorias analíticas em suas práticas discursivas, parecem continuar vítimas dos padrões de uma ciência moderna, reducionista $\mathrm{e}$ essencialista, que se manifesta em pequenos detalhes de sua linguagem, decisivos, contudo, no comprometimento e esvaziamento de sua mensagem. Por isso, no meio acadêmico continua-se a confundir campo com rural e cidade com urbano. (BIAZZO, 2008. p. $133-134)$

A partir da análise dos referidos livros didáticos, percebe-se que existem lacunas conceituais que induzem os professores a reprodução de estereótipos, o que dificulta que os alunos do segundo ciclo do Ensino Fundamental reflitam de forma crítica sobre esses espaços. O não debate sobre a construção e possibilidades conceituais leva a uma visão congelada da paisagem e acentua a ideia de rural e campo como sinônimos.

Trazer para os livros didáticos do segundo ciclo do Ensino Fundamental conceitos atualizados e críticos, é permitir que os alunos percebam que estes são reflexo do real e que a realidade é dinâmica, ou seja, leva o discente a perceber que:

[...] o conceito não se confunde com o real, ele é um reflexo do real, uma representação do real. Como ele é reflexo do real e uma representação desse, ele existe a posteriori dos objetos que representa. Já os objetos do mundo real existem independentemente dos conceitos. (LENCIONI, 2008. p. 111)

O conceito é uma generalização do real, sendo assim, ele precisa abranger o máximo de elementos possível existente na realidade conceituada para que possa possibilitar ao leitor um maior conhecimento da diversidade de características do objeto descrito. Assim sendo, os conceitos de rural e de campo não devem remeter a um rural ou um campo em particular, mas sim à diversidade que se estabelece no real. 
Ao não trabalhar os conceitos de maneira crítica, analítica e os seus processos de mutação ao longo do tempo, nota-se uma reprodução de estereótipos, principalmente por falta de conhecimento da diversidade da realidade e dos seus processos de transformação. Isto é o que acontece quando se retrata as paisagens rurais e as atividades no campo brasileiro, em muitos casos, caracterizando-os como locais atrasados, pobres, sem tecnologia, onde as pessoas passam fome, não têm estudo ou são preguiçosas. Muitas vezes essas características não necessariamente representadas por texto escrito, mas sim por desenhos e figuras. Ou seja, induz-se a uma homogeneização da diversidade existente no campo, sem levar em conta como esse espaço é produzido e transformado frente ao avanço das técnicas e tecnologias e do processo de urbanização,

No caso das coleções dos livros didáticos selecionados para análise, foi possível identificar alguns problemas recorrentes no que se refere à temática "campo e rural". Na coleção de Lima (2014c) há uma unidade com o seguinte título: "Campo: área rural do município". Apesar de o título conter um rápido indicativo conceitual sobre o campo, durante toda a unidade não houve o esclarecimento dos conceitos de rural e de campo e os dois termos foram colocados, em alguns trechos, como se tratasse do mesmo objeto. Esse título não está pautado em uma abordagem crítica, mas sim na conceituação de campo e rural segundo o IBGE, em que o município é dividido em área rural e área urbana e o campo está inserido na área rural. Complementando essa informação a colocação de Sobarzo cabe bem, onde ele afirma que: "O campo poderia ser entendido como a base prático sensível e o rural, a realidade social" (SOBARZO apud ARAÚJO; SOARES, 2009, p. 5). Essa complementação e esclarecimento conceitual devem ter, obviamente, a linguagem adaptada para se tornar pertinente aos alunos do ano de ensino correspondente.

$\mathrm{Na}$ mesma obra a autora inicia a referida unidade fazendo os seguintes questionamentos: "Você mora em uma paisagem rural ou já visitou alguma? Como a paisagem do campo está organizada?" (Lima, 2014c. p. 144). Ao fazer essa análise o livro deveria trazer, em algum momento, a reflexão sobre o conceito de paisagem. Para Santos (2008. p. 67-68) "Tudo o que nós vemos, o que nossa visão alcança, é a paisagem. Esta pode ser definida como o domínio do visível, aquilo que a vista abarca. É formado não apenas de volumes, mas também de cores, movimentos, odores, sons, etc." Ainda segundo Santos (2008. p. 68) "A dimensão da paisagem é a dimensão da percepção, o que chega aos sentidos. Por isso o aparelho cognitivo tem importância crucial nessa apreensão, pelo fato de que toda nossa educação, formal ou informal, é feita de forma seletiva".

A seguir a autora tenta esclarecer o conceito de campo e rural com o seguinte texto: "Se você vive em uma área rural ou já visitou alguma, deve ter percebido que há uma grande variedade de paisagens no campo. Essa variedade deve-se aos diferentes modos como as pessoas ocupam e transformam os lugares" (Lima, 2014c. p. 144). Há uma tentativa de se mostrar a diversidade de paisagens do campo e não cair no estereótipo, contudo, percebe-se que há uma confusão nas abordagens dos termos campo e rural, tratando-os como sinônimos.

A imagem a seguir também faz parte da primeira página da unidade mencionada do livro de Lima (2014c). A figura convida o aluno-leitor a ver a paisagem de um mesmo lugar em momentos diferentes. Nela é possível ler, por meio da análise da paisagem, que o campo sofre transformações, o problema é se o aluno entende esse aspecto como uma questão evolutiva, com a ideia de que o campo tende a ser cidade. No entanto, a imagem das paisagens, os questionamentos, os textos postos e os que seguem no decorrer da unidade não são capazes de esclarecer, por si só, a compreensão dos conceitos de rural e campo, título da unidade, é preciso que o professor possua uma abordagem crítica para explorar as possiblidades de compreensão de campo que está proposta. 


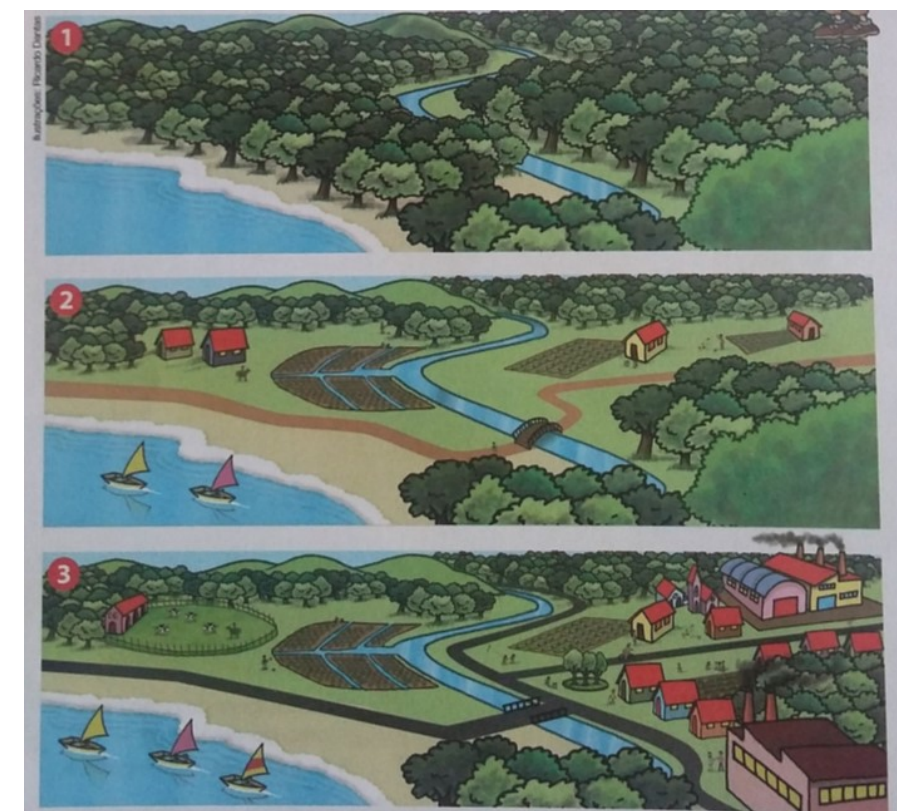

Fonte: LIMA, M. Geografia: Porta Aberta. 2014 p. 144

A forma como a ilustração é colocada e contextualizada no livro didático reproduz a continuidade da prática descritiva, herdada da geografia tradicional. Ressalva-se que a abordagem da análise geográfica por meio da paisagem deve se constituir como uma ferramenta para proporcionar ao aluno que ultrapassasse a paisagem como aspecto para chegar aos seus significados. Essa premissa, porém, não tem sido atingida nas obras analisadas.

Um dos maiores problemas encontrados nos livro didáticos de geografia do segundo ciclo do Ensino fundamental, quando se trata do rural e do campo, é a tendência ao estereótipo, de apresentar apenas um tipo de modo de vida e a oposição ao urbano. Apesar de toda diversidade das paisagens, do modo de vida e das atividades econômicas é mostrado o rural apenas ligado às atividades agrícolas e a pecuária, esquecendo de abordar que há várias formas e modos de vida no campo, desde as ruralidades às atividades não-rurais que são desenvolvidas, além das integrações entre campo e cidade. Sobre esta última questão Santos (2008) afirma:

Durante alguns séculos, campo e cidade interagiam mutuamente. Mas com o processo que se inicia com as grandes navegações e consolidase com a revolução industrial, já não é possível ficarmos imunes às mudanças e continuarmos com os mesmos conceitos e classificações hierárquicas. Quando Lisboa, Londres, etc., têm relações intensas com áreas distantes, de onde vem grande parte de suas riquezas, é pouco falarmos apenas em uma cidade que tem um campo do qual depende e vice-versa, ou antes, é incorreto. As relações com áreas distantes do campo imediato passa a ser uma constante, e mesmo uma necessidade. Mas a noção antiga perdurou, e ainda hoje, quando a vida rural às vezes se torna quase autônoma em relação à próxima cidadezinha, ainda encontramos incorretamente mencionado o tipo clássico de relação entre cidade-campo. (SANTOS, 2008. p. 60-61).

É possível perceber que deve-se falar numa variedade de modos de vida, atividades econômicas e sociais. Como exemplificação, pode-se dizer que o modo de vida do pescador, não é igual ao modo de vida do agricultor familiar, que em nada se assemelha ao do trabalhador cana de açúcar. Há também os trabalhadores que não exercem atividades ligadas ao setor primário no campo. 
A prestação de serviço é uma dessas atividades econômicas, que apesar de ser se realizar com mais intensidade e frequência nos centros urbanos, vem ganhando espaço entre as atividades econômicas no campo nas últimas décadas. Seguindo esta linha de pensamento, Carneiro (2005) afirma que no contexto atual não é possível conceber o rural exclusivamente como áreas agrícolas, e sim espaço de reprodução da vida de diversos grupos sociais.

Na unidade "Explorar paisagens" do Projeto Ápis (SIMIELLI, 2014b) o campo é apresentado na sua forma tradicional. As imagens associadas ao campo mostram uma casa isolada coma criação de ovelhas (e em outras imagens, que tratam do tema de forma transversal na coleção, o gado) de forma extensiva, semelhante à ideia de campo do século XIX descrita por Marx e Engels.

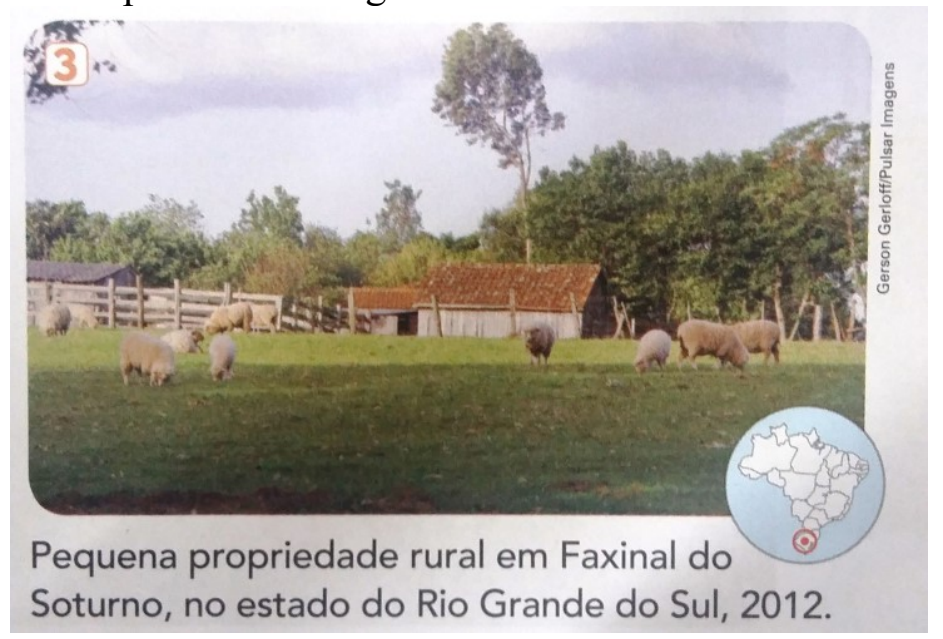

Fonte: SIMIELLI, 2014b, p. 126.

Não que essa paisagem não exista e não seja relevante para a compreensão do campo, mas se pautar apenas nela reforça a ideia do rural tradicional, de local isolado, sem tecnologia e tranquilo, podendo cair no estereótipo. Para Marx e Engels (2005), por exemplo, o rural é exatamente o oposto da cidade, isto é, a dispersão e o isolamento. Baixo adensamento populacional continua caracterizando o rural, mas merece algumas ressalvas, afinal, o que dizer dos condomínios que remetem a ruralidade nos municípios periféricos à cidade centro da metrópole? O bairro de Aldeia, no município de Camaragibe, localizado na Região Metropolitana do Recife, serve como modelo deste padrão. Apesar de elementos de urbanidade é caracterizado como uma área campestre e bucólica pelos moradores e residentes de fim de semana (ANDRADE, 2006).

A outra imagem é a de uma usina de cana de açúcar. Ela leva o aluno a refletir sobre as transformações que ocorrem no campo. A ideia é semelhante à de Lima (2014c) quando traz a imagem do mesmo local em diferentes períodos temporais (mencionado anteriormente).

A imagem da usina e plantação de cana de açúcar, contida em SIMIELLI (2014b, p. 126), segue abaixo com o seguinte texto: 


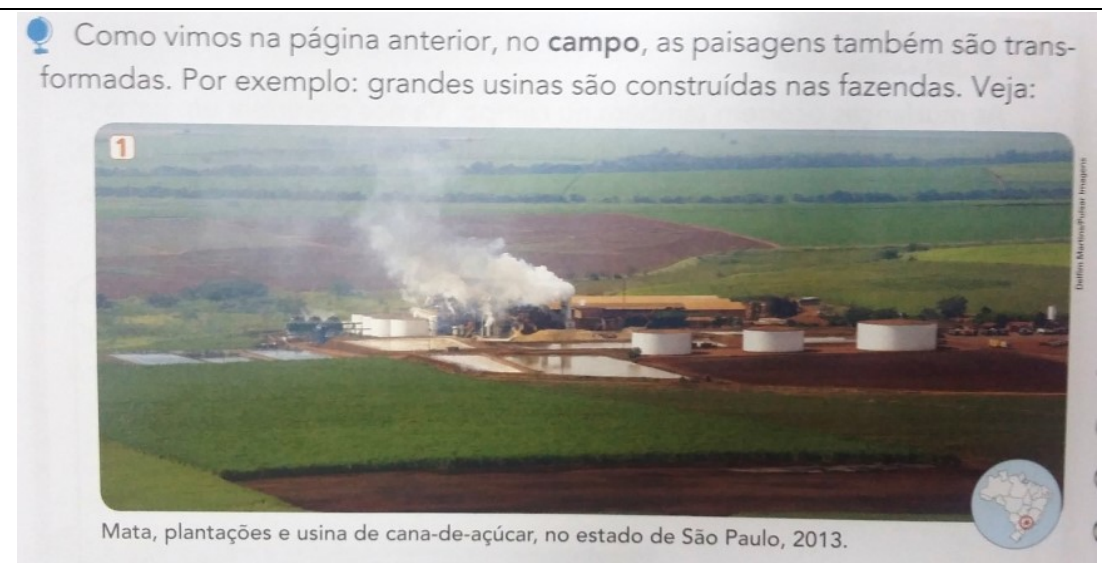

Fonte: SIMIELLI, $2014 \mathrm{~b}$. seguinte:

O texto da "página anterior" mencionado em SIMIELLI (2014b, p. 126) é o

As mudanças ocorrem também no campo. Vamos pesquisar em Jornais, revistas ou na internet imagens de uma bonita floresta e de uma floresta sendo desmatada ou já derrubada. Cole abaixo. Se preferir, faça desenhos. Depois explique o que aconteceu em cada situação. (SIMIELLI, 2014b, p. 125).

A partir desta citação, percebe-se um equívoco comum que é abordar o natural como sendo campo, contudo o campo é transformado e produzido pelo homem, mesmo com a predominância de elementos naturais.

Percebeu-se, nesta coleção, uma prioridade pela análise do espaço urbano. A explicitação do rural é colocada como oposição e de forma transversal. Essa percepção não exclui a condução positiva da obra em provocar os estudantes a perceberem as transformações da paisagem ao longo do tempo. Porém, deixa de lado as colocações do PCN (1998) de geografia, que indica que este ciclo deve tratar da formação socioespacial do campo e da cidade com maior profundidade. O PCN propõe ainda que esses conteúdos mostrem as suas pluralidades, permeado por temas transversais tal como a fome (PCN, 1998).

Apesar da crescente importância e redesenho do campo, os esclarecimentos sobre essas questões quase não formam tocadas nos livros didáticos, dando margem a construção de uma ideia estereotipada e de homogeneidade do rural e do campo. Ainda há pontos que deveriam passar por reflexões nas obras didáticas do ensino Fundamental I, tais como: Será um operador de uma máquina agrícola complexa pode ser considerado um agricultor? Qual a relação que esses trabalhadores de máquinas agrícolas tem com o local da produção agrícola? Serão eles moradores de bairros rurais?

Faz-se necessário lembrar que, via de regra, esse tipo de trabalhador nem reside no campo, mas sim na cidade mais próxima ao local da produção agrícola. A identidade desse trabalhador é com a operação da máquina de alta complexidade e não com o campo e a produção agrícola em si. Indo de encontro a essa colocação Lima (2014c, p. 96), trás o seguinte texto:

O trabalho agrícola

As pessoas precisam de alimentos para viver. Para obtê-lo elas ocupam terrenos e organizam plantações.

O trabalho que envolve o preparo da terra, o plantio e a colheita de vegetais chama-se agricultura.

As frutas (banana, laranja, melão) os cereais (arroz, soja, trigo), os legumes (feijão, vagem, chuchu) e as verduras (alface, agrião, espinafre) são produtos agrícolas. 
O profissional que trabalha na agricultura chama-se agricultor ou lavrador. Seu trabalho pode ser feito manualmente ou com o uso de máquinas. (Op. Cit. p. 96).

Todos os trabalhadores do campo compõe a dinâmica desse espaço, porém, nem todos esses trabalhadores se identificam com um modo de vida rural, cada vez mais os trabalhadores do campo são técnicos especializados em máquinas ou cientistas que não tem uma relação direta com o modo de vida rural, o que tem contribuído para a ampliação das urbanidades no campo. De acordo com Santos:

Como o campo se torna extremamente diferenciado pela multiplicidade de objetos geográficos que o formam, pelo fato de que esses objetos geográficos têm um conteúdo informacional cada vez mais distinto (o que se impõe, porque o trabalho no campo é cada vez mais carregado de ciência), tudo isso se faz com que a cidade local deixe de ser a cidade no campo e transforme-se na cidade do campo. (SANTOS, 2005, p 56)

O texto mencionado acima vem acompanhado de duas imagens que refletem a realidade da produção agrícola no Brasil.

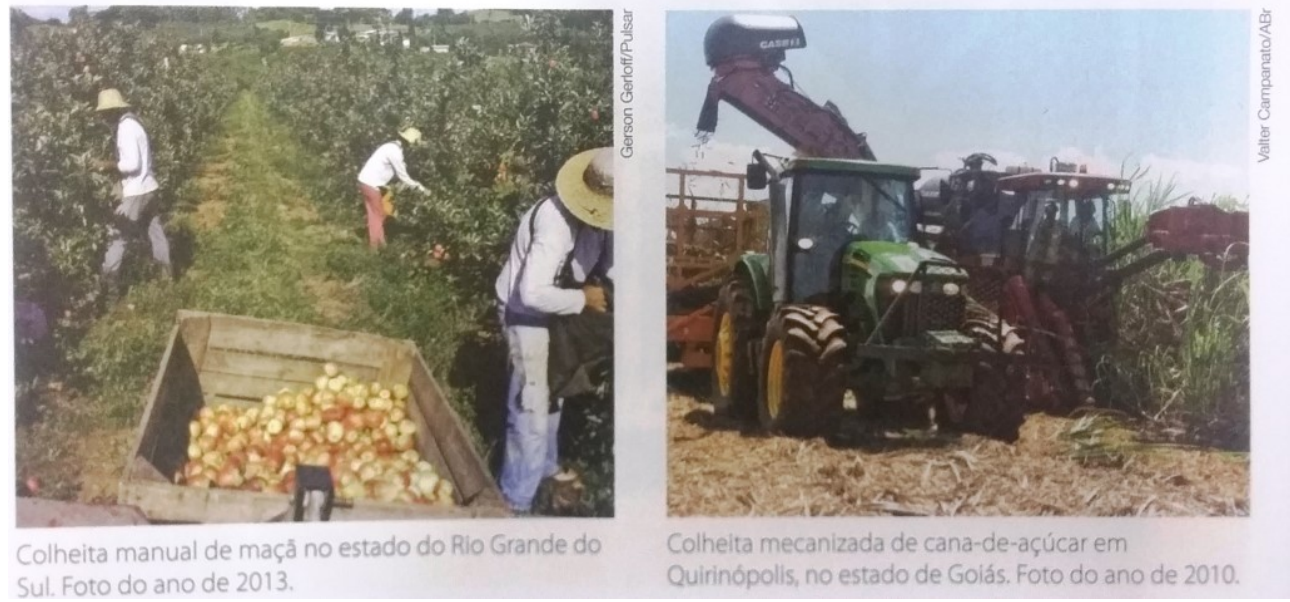

Fonte: Lima, 2014c.

A primeira imagem apresenta a produção de um modo tradicional, onde o agricultor realiza manualmente e diretamente a colheita. A segunda, a colheita de cana de açúcar, também representa uma realidade da produção agrícola do Brasil. Há, porém, a necessidade de se indicar que esses trabalhadores possuem uma melhor qualificação profissional, pois esse tipo de máquina é mais complexa de ser manuseada. Na região de Ribeirão Preto, por exemplo, os trabalhadores dessas máquinas residem nos centros urbano e pouco ou nada se identificam com o modo de vida rural e a atividade agrícola. Essa relação é um dos ponto que coloca a questão da articulação e complementariedade do rural com o urbano (e vice-versa), mas que não são postos para a apresentação dos alunos dos Ensino Fundamental I nos livros didáticos.

A diversidade de modos de vida do campo, na dinâmica socioeconômica e do modo de produção foi contemplada de forma mais adequada no Projeto Ápis, da Editora Ática, porém de forma transversal. Nele, as imagens trazidas apontaram parte da dinâmica do campo brasileiro, possibilitando construir a ideia menos estereotipada do campo.

A unidade "As paisagens do município" do livro didático de Lima (2014c) tem o título do seu primeiro tópico "A cidade e o campo". O esclarecimento conceitual de campo que existe nesta unidade é a seguinte: 
Você pode morar também em um lugar onde existem plantações, criações de animais e galpões industriais. Se for assim, você mora no campo. Nesse tipo de paisagem, as construções são mais isoladas, a concentração de pessoas é menor que na cidade e os elementos da natureza já sofreram modificações pela ação das pessoas.

As principais atividades realizadas pelas pessoas que vivem no campo são a agricultura, a pecuária e o extrativismo.

A cidade e o campo são diferentes não somente na sua organização e aparência, mas também no modo de viver e nos costumes das pessoas que vivem em cada uma dessas partes do município. Para ligar o campo à cidade, existem estradas e pontes. (LIMA, 2014c, p. 109).

Este texto do livro coloca o campo e a cidade articulados apenas pelos elementos fixos e não pelos os fluidos, como os diversos meios de comunicação existentes. Traz também uma ideia ultrapassada de oposição, e não uma interação dialética. Entender o campo e a cidade é algo complexo e por este motivo não deveria ser abordado de forma simplória e quase determinista. Há inúmeras questões que perpassam sobre compreender a reprodução dos espaços e suas articulações.

São diversos aspectos que que repetem nos livros didáticos não contribuindo para a construção de um conhecimento mais crítico e próximo do real no que diz respeito à análise do rural e do campo. Mesmo sendo um tema complexo, não se deve abordar de forma simplória por ser um tema trabalho no segundo ciclo. É preciso abordar de forma crítica, ressaltando a diversidade das paisagens e das relações que se estabelecem nestes espaços.

\section{CONSIDERAÇÕES FINAIS}

No segundo ciclo do Ensino Fundamental o ensino da geografia deve priorizar, entre outros conteúdos, a abordagem sobre o campo, o rural, o urbano e a cidade. $\mathrm{O}$ enfoque dado deve possibilitar ao aprendiz a compreensão da multiplicidade do espaço geográfico, fazendo com que eles conheçam as categorias de análise geográfica, tal como a paisagem. Durante a análise das coleções dos livros didáticos foi possível perceber que a discussão sobre rural e campo, de forma geral, não foi abordada de forma crítica, não contemplando a proposta do $\mathrm{PCN}$, nem o conhecimento acadêmico que vem sendo produzido nos últimos anos. Assim sendo, não possibilita um bom entendimento de questões político-administravas, populacionais, atividades econômicas e modos de vida, e toda complexidade que envolve a compreensão do rural e do campo.

Nesse sentido, essa pesquisa possibilitou perceber que a utilização da paisagem é feita principalmente de forma descritiva, indicando que a geografia produzida na academia pouco dialoga com a geografia dos livros didáticos do segundo ciclo do Ensino Fundamental. As categorias relações sociais de produção, modos de produção, meios de produção, forças produtivas e formação social, apesar de fundamentais para entender o rural e campo, uma vez que leva os alunos a desvendarem os seus cotidianos e as transformações do espaço, foram abordadas de forma superficial.

Os processos, estruturas, funções e formas que permeiam o rural e o campo não são frequentemente contemplados, uma vez que os textos apresentados nos livros não possibilitam o aprofundamento nas temáticas que explicitam as relações de interdependência e articulação. Apesar de indicar o processo de urbanização do campo, não esclarece que esta tendência vem ocorrendo de forma heterogênea. A indicação de que ora os espaços são comandados pela cidade, ora pelo campo fica esquecido pela tendência de apresentar a cidade como o comando do desenvolvimento e centralidade econômica. 
O campo, na coleção Ápis da Editora Ática, foi analisado como uma paisagem imutável e como um local que representa um momento da etapa do desenvolvimento social. Desta forma, transmite a ideia de que o campo é uma área a ser suplantada com o avanço da urbanização. Desta forma, fez-se necessário, para esta coleção, uma aproximação da evolução do conceito de rural e campo, a fim de minimizar a construção de estereótipos, além de apresentar a diversidade do rural, os elementos de ruralidade no urbano e as relações estabelecidas entre o urbano e o rural. Ainda nesta coleção, o maior enfoque da relação campo - cidade foi a de que o campo é produtor de matérias primas para a cidade, sem apresentar o processo produtivo das mercadorias.

Com isto, mostrar aos professores e as editoras as lacunas deixadas nos livros didáticos se faz necessário por despertar para compreensão mais ampla do espaço sociocultural ao qual pertence e ao qual pertencem os outros. Construindo o respeito à diversidade cultural e contribuindo para a desconstrução de práticas pedagógicas generalistas, tradicionalistas e estereotipadas.

\section{REFERÊNCIAS}

ABRAMOVAY, Ricardo (2003 a) - "Funções e medidas da ruralidade no desenvolvimento contemporâneo" in O Futuro das Regiões Rurais pp. 17-56 - Ed. UFRGS, Porto Alegre.

ALBUQUERQUE, M. Geografia na prática pedagógica: a paisagem como ponto de partida. In: Rev. Tamoios, São Gonçalo (RJ), ano 10, n. 1, pags. 30-40, jan/jun. 2014

ALBUQUERQUE, M; MACHADO, M. A paisagem na Região Metropolitana do Recife: Permanências e Transformações. In: O rural e o urbano na Região Metropolitana do Recife. ALBUQUERQUE, M; MACHADO, M (Orgs.). Garanhuns: Ed. UFRPE, 2015.

ANDRADE, Ana Karina Nogueira de. O lugar em Aldeia: significados, valores, percepções e atitudes dos moradores dos condomínios residenciais de Aldeia, Camaragibe-PE. Recife, 2006. 299 folhas Dissertação (mestrado) - Universidade Federal de Pernambuco. CFCH. Geografia.

ARAUJO, Flávia A. Vieira de; SOARES, Beatriz Ribeiro. Relação cidade-campo: desafios e perspectivas. In: Campo-território: Revista de geografia agrária, v.4, n. 7, p. 201-229, fev. 2009.

BRASIL. Secretaria de Educação Fundamental. Parâmetros curriculares nacionais: geografia /Secretaria de Educação Fundamental. Brasília: MEC/SEF, 1998.

BIAZZO, Pedro Paulo. CAMPO E RURAL, CIDADE E URBANO: distinções necessárias para uma perspectiva crítica em geografia agrária. In: Encontro Nacional de Grupos de Pesquisa - ENGRUP, 4º , 2008, São Paulo. Agricultura, Desenvolvimento Regional e Transformações Sócio-Espaciais - Mudanças na cidade e no campo contemporâneos: novas ruralidades em construção (p. 132 - 150).

CARLOS, Ana Fani Alessandri. A cidade. São Paulo: Contexto, 2005.

CARNEIRO, M. J. (2005) "Apresentação" In: MOREIRA, J.R. (org.). Identidades sociais: Ruralidades no Brasil contemporâneo. Rio de Janeiro: DP\&A, pp.7-13.

ELIAS, Denise. Ensaios sobre os espaços agrícolas de exclusão. In: REVISTA NERA. Rio de Janeiro (RJ), ano 8, n. 8, jan./jun. de 2006 - ISSN 1806-6755

GRAZIANO DA SILVA, J. O novo rural brasileiro. Campinas: UNICAMP, Instituto de Economia, 2002. 153p

LEFEBVRE, Henri. O direito à cidade. São Paulo: Centauro, 2001.

A revolução urbana. Belo Horizonte: Ed. UFMG, 2004. 
LENCIONI, Sandra. Observações sobre o conceito de cidade e urbano. GEOUSP Espaço e Tempo, São Paulo, No 24, pp. 109 - 123, 2008

LIMA, Mirna. Porta Aberta: geografia, $3^{\circ}$ ano $-1^{a}$ ed. - São Paulo: FTD, 2014c. Porta Aberta: geografia, $5^{\circ}$ ano $-1^{a}$ ed. - São Paulo: FTD, 2014d. . Porta Aberta: geografia, $5^{\circ}$ ano $-1^{a}$ ed. - São Paulo: FTD, 2014e.

MARAFON, Gláucio. Campo, relações campo-cidade e luta pela terra In: Geografia: ensino fundamental. BUITONI, Marísia Margarida Santiago Buitoni (coord.). Brasília: Ministério da Educação, Secretaria de Educação Básica, 2010.

MARQUES, Marta Inez Medeiros. O conceito de espaço rural em questão. In Terra

Livre, 19. São Paulo: AGB, 2002 (p. 95 - 112).

MARX, Karl; ENGELS, Friedrich. A ideologia alemã. São Paulo: Editora Martin Claret, 2005.

RUA, João. Urbanidades no rural: o devir de novas territorialidades. Campo e Território: Revisa de Geografia Agrária, Uberlândia, v.1, n.1, p.82-106, fev. 2006. Disponível em: www.campoterritororio.ig.ufu.br.

SANTOS, Milton. Metamorfose do espaço habitado. 6.ed - São Paulo: Editora da Universidade de São Paulo, 2008.

. A urbanização brasileira. São Paulo: Edusp, 2005.

SIMIELLI, Maria Elena. Projeto Ápis: geografia: Ensino Fundamental I; assessoria técnico-pedagógica Anna Maria Charlier. - 2. Ed. - São Paulo: Ática, 2014.

. Projeto Ápis: geografia: Ensino Fundamental I; assessoria técnicopedagógica Anna Maria Charlier. - 2. Ed. - São Paulo: Ática, 2014b.

Projeto Ápis: geografia: Ensino Fundamental I; assessoria técnicopedagógica Anna Maria Charlier. - 2. Ed. - São Paulo: Ática, 2014c.

VEIGA, José Eli da. Cidade Imaginárias: o Brasil é menos urbano do que se calcula. 2. Ed. Campinas, 2002.

WILLIAMS, Raymond. O campo e a cidade: na história e na literatura. São Paulo: Companhia das Letras, 2011.

http://www.ibge.gov.br/home/estatistica/populacao/mapa_mercado_trabalho/notastecnic as.shtm < Acesso em: janeiro de 2016> 